\title{
LAS CREADORAS DE ESCENA Y EL VOYEUR. NUEVOS FORMATOS EN CLAVE DE MUJER, QUE ASALTAN LOS ESCENARIOS MADRILEÑOS
}

\author{
THE SCENE CREATORS AND THE VOYEUR, NEW FORMATS IN WOMEN'S KEY \\ THAT STORM MADRILEAN SCENARIOS
}

Julio Castro Jiménez

Redactor en Red Escénica

\section{Resumen:}

En este artículo se realiza un recorrido por el panorama teatral madrileño femenino. Se habla de autoras de teatro en español de actualidad, sus modos de creación, los temas $\mathrm{y}$ géneros trabajados y sus inquietudes. Se exponen también las diferentes compañías de teatro en las que todas o prácticamente todas las integrantes son mujeres, su funcionamiento, estilo de trabajo y medios, así como los espacios, las salas alternativas más importantes de Madrid. Se dedica un espacio a la danza y a los eventos dedicados a esta, como el Festival Internacional de Danza Miradas del Cuerpo, y también a los espacios de formación teatral no formales, cursos, seminarios y escuelas. La autora también analiza el teatro infantil o familiar, la presencia de mujeres en este y sus objetivos principales.

\section{Palabras Clave:}

panorama teatral madrileño, salas alternativas, dramaturgas, danza

\section{Abstract:}

This article takes a tour of the Madrid female theater scene. It talks about current Spanish theater authors, their modes of creation, the themes and genres worked on, and their concerns. The different theater companies in which all or practically all the members are women are also exposed, as well as their operation, work style and media, as well as the spaces, the most important alternative rooms in Madrid. A space is dedicated to dance and to the events dedicated to it, such as the International Dance Festival Miradas del cuerpo, and also to non-formal theatrical training spaces, courses, seminars and schools. The author also analyzes children's or family theater, the presence of women in it and its main objectives.

\section{KeYWORDS:}

Madrid theater scene, alternative rooms, playwrights, dance 
Ella: Escucha esto: “Implantan una mini-cámara orgánica en un espermatozoide para poder observar al feto durante la gestación. Posteriormente, permanecerá funcionando alojada en el bulbo raquídeo hasta cinco años después de la jubilación." Él: ¿Cinco años nada más?bueno, supongo que voluntariamente se podrá prorrogar todo el tiempo que quieras. Ella: Pues no te confíes, que como está la cosa, lo mismo nos recortan hasta la libertad de observación. (ados@dos, de Petra Martínez y Juan Margallo).

Desde hace años, nos encontramos ante una explosión artística que en estos momentos encabeza la creación teatral en las salas alternativas o de pequeño formato en Madrid, en la que el papel más relevante parece haber sido abordado por las mujeres, ofreciendo una visión diferente que, a mi modo de ver, matiza o transforma todo lo preexistente. Sin embargo, mientras que en cuanto a las visiones diferentes la actriz, directora y profesora Angélica Briseño, me dice "más allá de que sea de mujer o de hombre, creo que es de persona, de forma de concebir las cosas, de sentirlas y de verlas. Pero sí hay una diferencia. Aunque no sé exactamente si es una diferencia de género o de persona. Puede que sea mi forma de ver las cosas"(Castro 2010r), la directora y programadora Marina Skell, afirma: “la mirada masculina es diferente a la femenina. Ni mejor ni peor: es diferente. Creo que hay una sensibilidad diferente, y ya solamente por eso, hay otros caminos, otras formas de ver determinadas situaciones, pero creo que también es muy enriquecedor" (Castro 2010: Entrevista a Marina Skell, 11-09-10 -pendiente de publicación-). Son dos de las mujeres que desarrollan su labor teatral en Madrid desde hace años. Creo que la diferencia de edad no hace marcadas distinciones en esta opinión, así que no he querido centrar mi análisis y exposición en algo que, por fuerza de nacer de la subjetividad de cada persona, no puede ser tomado en consideración para establecer un criterio objetivo concluyente. Otra cuestión es considerar los campos tan diferentes en los que las mujeres han ocupado el espacio teatral en el lugar más profundo de la creación, la innovación o la apuesta por los dos ámbitos, garantizando una pervivencia que durante décadas se consideró en riesgo en nuestro país. Me interesa porque no hablamos de puestos ocupados por designación o por cuestiones económicas, sino por esfuerzo, mérito, compromiso o, sobre todo, gracias a la nueva concepción que una generación nueva de actrices y actores, de dramaturgas y dramaturgos, de gestoras y gestores de salas, de docentes y otras personas ligadas al hecho teatral, se ha dedicado a transformar desde una visión de desequilibrio de la mujer respecto al hombre, a fin de concebir la escena como resultado de un ensamblaje entre los esfuerzos y capacidades de quienes las integran. Podría hacer un repaso de ellos y ellas en relación de unos con otras, pero es un trabajo más largo y pendiente. Creo más inmediato y necesario reseñar la importancia de la actualidad teatral que recrean las mujeres en algunos de los distintos ámbitos que he podido observar en la escena que se desarrolla en Madrid y, concretamente, allí donde (a mi parecer) nace 
lo más elemental y más rico de la creación teatral: las llamadas salas alternativas o de pequeño formato.

Reclamo así mi "libertad de observación" (como parodia Petra Martínez junto a Juan Margallo en otro sentido en su obra ados@dos), con la discreción y el respeto que merecen quienes integran este medio cultural, y con la pequeña indiscreción de quien a veces al observar, comprende una tercera dimensión, más allá de la simple pantalla plana que dejarían los viejos telones teatrales al terminar la obra. Así, me mostraré como el "voyeur" que quiero ser, del significado, evolución y resultado que se genera hoy, para continuidad y crecimiento mañana en este medio cultural.

\section{AUTORAS Y DRAMATURGAS}

Probablemente es el origen de todo, porque la persona que ama el teatro ya sea como medio de expresión, ya como forma de comunicación, fácilmente se ve atraída y tentada de acercarse más a una creación más real, así como al contacto con el público. En este sentido, las escritoras que acaban participando de su propia creación son numerosas, aunque también existe el camino inverso, que pudiera parecer más natural, el de la actriz o directora que acaba por escribir sus propios textos. La primera vía, parece haber agotado los nuevos círculos de la creación teatral, para ser reemplazada por mujeres que, antes que provenientes del mundo literario (o además de ello) proceden del teatro y, consiguen así imprimir un doble sello diferente a la hora de plasmar su propuesta. Me sorprende que, en ocasiones, sean las mujeres más jóvenes aquellas que cuentan con una mayor producción dramatúrgica o literaria, o las que se correspondan con textos de una seriedad y ámbito documental más elaborado. En este sentido, la burgalesa María Velasco González, a partir de su texto Perros en danza (intrahistorias de la república y la guerra) (Álvarez 2010), demuestra que la edad no es un límite para plasmar una propuesta históricamente bien construida, que se sale de lo establecido para reflejar una realidad bien documentada, sin necesidad de aburrir al público o de limitarse a la literalidad para narrar la guerra civil española y la postguerra. En este sentido, para la puesta en escena de la obra en la RESAD, la autora afirma que "decidimos que no queríamos respetar el proceso de producción tradicional en el que el texto es la punta de lanza del montaje, o bien, todo surge a partir de la propuesta unidireccional del director". El resultado es un trabajo formidable que debiera apoyarse como modelo y como resultado. En el sentido creativo, María nos dice que "a lo largo del siglo XX, se incidió en la diferencia entre literatura dramática y el teatro como hecho escénico. Yo apuesto por una hibridación de la palabra y la escena", y esta parece ser, precisamente, la línea de otras autoras que ven en esa hibridación que manifiesta María Velasco, un hecho indisociable, aunque no lo expresen en palabras, sino en resultados. 
Joven y nueva en el ámbito de la autoría dramática es la sevillana Victoria Herrera, con un trabajo que entronca con la temática del anterior, a la vez que contrasta con el mismo en cuanto al tono más serio. No me cabe duda de que ambos trabajos profundizan en las raíces históricas de un asunto, tan cercano a los hechos de esa guerra contra el fascismo, perdida en España en los años '30, que aquí protagonizan las presas del franquismo. La diferencia fundamental se encuentra en el tono en que expone Victoria su obra Irredentas, que refleja el fruto de un trabajo de investigación a partir de fuentes directas, lo que le permite tratar el tema en primera persona. La seriedad de ese trabajo facilita que se pongan más trabas a la distribución y puesta en marcha de su obra, lo que demuestra que, mientras nuestra sociedad ha madurado (tal y como ella esperaba), no todos los responsables institucionales lo han hecho, más allá de la propia farsa. La característica principal de esta dramaturga es afrontar las dificultades, empeñada en no abandonar su trabajo.

Para mí, una autora por excelencia es, sin duda, la uruguaya Denise Despeyroux, que se mueve esencialmente entre Barcelona y Madrid. En el Teatro LaGrada primero, y en la sala Cuarta Pared más tarde, donde tuve ocasión de asistir a La muerte es lo de menos (Castro 2009e), pero también de coincidir con ella y de tener acceso a varios de sus textos dramáticos, donde compruebo que una motivación diferente aporta un nuevo estilo dentro de lo absurdo, para hacer que el espectador decida si toma posición ante lo se le muestra, sin que sea preciso orientarle en el camino de ese proceso, sino en plena libertad ante lo que percibe. Para explicar este posicionamiento, la autora y dramaturga me expone la siguiente reflexión "cuando un espectador va a ver una obra de teatro mía no tiene por qué interesarle lo que yo piense sobre nada en cuestión, lo único importante es que encuentre allí un mundo nuevo capaz de seducirlo y de hallar alguna resonancia en el suyo propio". Así, Denise concibe el teatro como "territorio de libertad, de descubrimiento y de goce" en esos términos. Sus textos son un placer que engancha al lector (o al espectador), y en su lectura no es posible esconder la sonrisa o la risa durante la lectura de los mismos ante las situaciones que plantea, tan calcadas de la absurda realidad con que nos acosa en sus obras. Recomiendo leerla por la calle, para ser observado con recelo, como al uno de sus locos protagonistas.

Cierto aire de locura cotidiana rodea a Vanessa Palomo Llanos, otra autora y dramaturga, con la peculiaridad de escribir junto con las actrices de su compañía Pombo Teatro, o contar con su colaboración para crear los personajes a la hora de generar los textos. Todo comienza en una parodia de velocísimos sketches, en los que la autora explica que "el tema sería crímenes en la vida cotidiana", la idea inicial era de tres piezas teatrales cortas que luego se engranaron en una. La conexión del primer trabajo, Matar x Matar (Castro 2010g), con el teatro de Despeyroux se centra en lo absurdo de la realidad, una cuestión recurrente que podremos observar más tarde 
en los Monstruos de Marina Wainer. En un tono diferente, y siempre con toques de humor inteligente, la propia Vanessa crea por encargo Cáscara Amarga (Castro 2010h), una línea muy próxima a las mujeres (aunque dirigida a cualquier adulto con sentido de la crítica y del humor), donde comparten protagonismo por igual la discriminación de género, la auto-represión, y ese cambio generacional, respecto a lo que se arrastra de un pasado reciente. El teatro de Vanessa y de Pombo Teatro intenta "crear cosas originales y con puntos de vista nuevos, y siempre, aunque hablemos de cosas serias, con un toque de humor": hasta ahora lo consiguen, y mantienen sus obras en cartel durante meses.

En este mismo entorno, cerrando la línea del absurdo realista, tenemos a la argentina Marina Wainer, que no es ninguna novel en la autoría teatral, sino que cuenta con una muy extensa trayectoria en todos los aspectos artísticos del ámbito teatral, y con una obra muy ligada al teatro sobre mujeres, cuestión que no sólo no la limita, sino que parece darle alas para abarcar todo tipo de aspectos que implican solidaridad en el último trabajo escrito y dirigido por ella, bajo el nombre de Monstruos, producido por la sala Pradillo en el verano de 2010, obra en la que podemos contemplar todo tipo de seres aberrantes de nuestra sociedad, (anticipa Marina: "los personajes reales les parecerán ficción...y la ficción, tan real que aunque lleve una corona creerán haberla visto en la fila del mercado") incluyendo entre ellos, a quienes contemplan el maltrato a las mujeres, o a los mismos espectadores, que pueden ser parte de esos monstruos en la forma de mirar y de comprender algunas de las escenas. Más allá de su grandísimo sentido de la observación y del humor con que se desarrolla, es una obra transformadora de quien la ve, pero también de sus intérpretes a través de los ojos del público. La propuesta de la autora es la siguiente: "riámonos de ellos como ellos tantas veces, se han reído de nosotros; demos con la risa en sus narices"'. El formato cercano al cabaret, y rayano en la realidad consigue atrapar para el público elementos de nuestro entorno cotidiano, transformándolo en sorpresa. Como contraste, este trabajo llega apenas pocos meses después de El cuerpo deshabitado, con otro enfoque en el que, no deja de tratar de plasmar la concepción esa realidad desde otros puntos de vista.

En un entorno bien distinto encontraremos a Rocío Mostaza, con la que inicio un recorrido más complicado, como es el llamado teatro para todos los públicos, es decir, el que abre el teatro a la infancia. Y creo que es el más complicado de los ámbitos de trabajo, porque su público no tiene límites. En este entorno, la actriz y dramaturga elige un tema duro, ya que hablar a la infancia desde la visión de un niño, requiere de posiciones arriesgadas, especialmente cuando se trata de conducir el argumento por la vía del compromiso social, en el que se abarcan las diferencias económicas, las diferencias culturales o cómo tratar de evitar las discriminaciones a unos seres humanos respecto a otros. Así, este trabajo con el título de El Lazarillo ¡Un niño de 
mundo! (González 2008), reúne a Raquel Mesa, Nuria Pascual, Claudia García y Susi Posilio (y a dos músicos en escena), juega a intercambiar el personaje de Lázaro entre las actrices, mientras mueve el foco entre las adultas y el pícaro inocente, como una moviola de tiempo, con protagonistas de otro género.

Milagro Lalli, además de su dualidad danza-teatro, ejerce la labor docente, y ante el desafío de la sala Cuarta Pared, para realizar un montaje propio dirigido a la infancia, se compromete a "seguir siendo fiel al código de comunicación que a mí me interesa, y no subestimar la capacidad intelectual de los niños". Al tratar su creación desde lo teatral para abordar luego la parte de movimiento con actores que no son bailarines, Milagro me señala que no puede afirmar "que se encare desde la danza o el teatro. Personalmente es algo que cada vez, pienso menos, yo hablo de un trabajo plástico, en todas sus formas”. Así da el primer paso para generar un trabajo como ¡Vaya Regalo!

Dentro de un realismo crítico cercano al de María Velasco, pero en otro formato, podemos englobar otro tipo de la obra Lo he visto en la tele, entonces será verdad..., de Marta del Puerto, en el cual por medio de la crítica humorística, inteligente, mordaz a veces, más inocente otras, diseña un panorama que recoge casi todo nuestro entorno sociopolítico, primera obra larga que escribe la autora tras varios relatos. La autora escribe y realiza trabajos de interpretación desde que hace años abandonara su profesión de ingeniería para dedicarse a su auténtica vocación, que es la escena. El hecho de que su trabajo artístico en la compañía Desheredadas sea exclusivamente con mujeres, no tiene un motivo tangible, sino que, para ella "es una decisión instintiva o intuitiva", pero sea como sea, el resultado es muy bueno y muestra gran adaptabilidad al momento, el lugar y el tipo de público, con una evolución consciente en el tiempo.

Marina Muñoz, que además de escribir textos teatrales, es actriz y productora de otras obras, plantea algo cercano a muchas de las mujeres de las que trato en este artículo: la necesidad de divertirse en su trabajo, como valor añadido a la necesidad del teatro. En sus propias palabras, "trato divertirme, permanecer sobre el escenario todo lo que pueda, avanzar y jugar y 'confeccionarme' los personajes que me apetece hacer". Tras verla por primera vez en Titanias, un trabajo escrito e interpretado por la propia Marina y por Vicky Castillo, he asistido a otros trabajos en los que participa como actriz. En esa obra, que trata en tono de humor la discriminación de las mujeres por su elección como lesbianas, ella se siente muy satisfecha, porque el cambio de tono respecto de otros trabajos en los que había participado, le ha facilitado acceder a papeles más "alocados, histriónicos, inconscientes, inocentes". En cuanto a la creación de sus obras, afirma que lo hace en buena medida porque "al escribir los textos imaginas cuál es el personaje que quieres hacer".

\section{EN COMPAÑíAS DE MUJERES}


Por lo que he podido extraer de las entrevistas o el intercambio de información con las protagonistas, formar una compañía en la que todas o prácticamente todas las integrantes sean mujeres, no es algo intencionado, sino que surge así $y$, si funciona, se perpetúa. En muchos casos, los resultados son buenos, como por ejemplo en La Xirgu IndieAir, integrada por Carmen Del Conte, Ana Astorga, Ana Adams y Patricia Jordá y que surge en 2008 y "que aboga por la iniciativa personal y la autogestión como fórmula de trabajo" en este sentido, me señalan que su "objetivo es lograr un medio que nos permita el desarrollo de la creatividad y la fantasía, manteniendo una actitud crítica y de denuncia con el sistema que nos acoge y nos coarta", y añaden que desde sus inicios querían "hacer un teatro sobre la mujer, la ansiedad, las exigencias de ésta, la obligación que impone la sociedad de que seamos buenas profesionales, físicamente bellas, siempre arregladas, buenas madres, cuidemos del hogar, constantes exigencias estéticas en revistas, televisión... Queríamos hacer un teatro que criticara esta situación". Así es como se muestran en Le Petit Cabaret des horreurs et des perversions, tal y como señalo en un artículo de principios de 2010. El público debe saber "apreciar los puntos de sentido crítico que se introducen en cada una de las historias, que seguramente es una de las principales finalidades del texto y del montaje, más allá del puro entretenimiento, y que, seguramente, sus autoras sabrán agradecerlo en quienes así lo comprendan" (Castro 2010a). Precisamente este trabajo es el que me hace consciente de la actualidad de la mujer en el teatro, en una sensación que venía percibiendo desde hacía tiempo, pero que en ese mismo momento quise constatar. Su segundo trabajo, Mise en Scène, una profunda crítica al entorno que viven las protagonistas de series televisivas, posee un carácter diferente, y sin embargo saben darle raíces comunes, mostrando al público que poseen un estilo definido. Por su parte, Pombo Teatro es una compañía en la que tres actrices y una dramaturga, desarrollan trabajos muy cercanos a las mujeres con un mensaje que muchos varones debieran ver y ser capaces de interiorizar. Vanessa Palomo como dramaturga y directora, Pili Palomo, Laura Garmo y Paloma del Campo como actrices, son el núcleo escénico de la compañía, que interpreta sus propios trabajos, en los que podemos ver Matar x Matar, y Cáscara amarga, dos trabajos que comentamos en el apartado de Autoras y dramaturgas. En esta compañía prima el humor, tras el que subyace la crítica salvaje a determinadas actitudes, que provienen en un caso de la violencia personal y cotidiana, pero también abarcan la discriminación sexual y la marginación de las mujeres en su elección, desde la situación que tres mujeres de distinta edad y posición, sufren ante su opción como lesbianas, ante el punto de mira en su respectiva situación social y educacional. Desheredadas Teatro es la compañía por la que más mujeres han pasado como integrantes: Aida Rivas, Lucía Piquero, Gloria March, Camila Redondo, Carolina Peinado, Carol Nere Rodríguez, Sara Villanueva y Marta del Puerto. Ésta última, Marta, es impulsora desde el inicio de la 
compañía, y dramaturga de la obra que vienen representando desde junio de 2009 Lo he visto en la tele, entonces será verdad... En cuanto a su forma de entender el trabajo, Marta me explica que para ellas "el teatro es algo que debe mantenerse vivo en cada función, a pesar de la repetición. Para mantenerlo vivo hay que construir algo nuevo cada vez que nos subimos a un escenario, hay que "volver a empezar". El espíritu crítico y de denuncia consiguen dar actualidad y revitalizar una serie de planteamientos que el espectador debe analizar en su entorno, sacando sus propias conclusiones. El estilo de su trabajo se puede poner a caballo entre el cabaret de La Xirgu, aunque menos clásico, y el de los sketches de Pombo Teatro, pero con un estilo que profundiza más en los temas tratados. No todo es humor en su trabajo, pero sí se muestra como un eje conductor importante. Clownas, compañía de payasas, ofrece un formato muy distinto de las anteriores. El clown es uno de los estilos que se sale del resto de los formatos teatrales más convencionales, aunque desde hace décadas, viene calando en los demás, de manera que éstos recogen las aportaciones del nuevo payaso a modo de innovaciones adecuadas a otras ofertas. Este grupo de mujeres, compuesto por Ana Serzo, Mireya Castizo, Elisa Niño, Ruth Franganillo y Valentina Bassi, por medio de la dirección de Joaco Martín, ofrecen desde 2007 un conjunto de espectáculos individuales, en los que "cinco mujeres de nariz roja, a través de situaciones cotidianas, o no tanto, nos muestran sus emociones a corazón abierto, nos cuentan sus pequeñas y grandes historias, y nos regalan lo mejor y lo peor de sí mismas" (Clownas 2010). Las participantes en la compañía, que tienen diversos orígenes de la geografía internacional, cuentan con espectáculos consecutivos, interaccionando tan solo en los interludios y cambios de escenario. No actúan todas en cada función, sino que se reparten a fin de que no dure más de 60' en total. La realidad y la ficción son tratadas en cada uno de sus espectáculos, mezclando ambas cosas de la manera más natural e hilarante. Casualmente, Elisa Niño, integrante de las Clownas, pertenece también a la compañía Dale que Dale Teatro, un equipo formado por cuatro actrices, para las que una dramaturga, Blanca Suñén, crea sus dramaturgias de acuerdo con las actrices en un trabajo de equipo en el que, si bien es ella la encargada de poner la carne en el asador de las letras, el intercambio entre las partes, no sólo es previo, sino que continúa una vez la obra ya está en marcha. En una entrevista realizada a la compañía (Castro 2010e), Isabel Romero de León dice "casi todas las obras están escritas por hombres y para hombres. Pero hay buenísimas dramaturgas mujeres, sobre todo a partir del siglo XX, y conocemos a muchas. Pero están dando un punto de vista diferente, sencillamente, porque antes no podían. Así que de lo que hablan es distinto", afirman que no pretenden dirigirse a mujeres, y Analía Tarrío-Lemos dice "reivindicamos el papel de la mujer en cuanto a salir de esos clichés en que nos han encasillado y decir que las cosas no son así". De quienes he entrevistado en estos años, ellas son de las más abiertamente críticas, de manera 
que Carmen Vera afirma que "en este país no existe una cultura teatral, ni de danza, ni de muchas cosas en general [...] hay programadores que te programan y luego te vetan bolos, porque cuando comprenden lo que estás diciendo, no interesa. Porque el teatro aún tiene mucho poder". Por su parte, Elisa Niño dice que "lo que te tienes que buscar es cómo no dejar de contar y hacer lo que haces, ver de qué modo llegar. Es también nuestra función". Su trabajo colectivo del año pasado lleva por título No hay perdiz en el menú, donde las clásicas princesas de los cuentos de hadas, rompen los esquemas para hacer pensar sobre lo que han representado y representan en la cultura universal, así como en la incultura de la discriminación. Cada una de ellas lleva otros proyectos teatrales aparte, además de dedicarse a la enseñanza teatral, pero esta asociación ha tenido un excelente resultado, muy recomendable.

Muchas mujeres se han adentrado en el género unipersonal, más sencillo de promocionar, por cuanto que precisa de pocos medios y se ha adaptado a los cafés con espectáculo, tan proliferantes. Pese a lo que parece, no es un género sencillo, porque si no innovas respecto a otros actores, acabas por ser uno más que se diluye en la larga lista. Tenemos autoras como de Victoria Siedlecki, con sus Relatos eróticos, que se mueve entre lo humorístico y lo sensual o la Leona de María Miguel, más autobiográfico, y siempre con humor. De entre todo lo visto, destaco a Ester Bellver, actriz que ha pasado por todos los formatos y las más grandes compañías de este país, desde el teatro clásico hasta el moderno, con el CDN, y la CNTC. A veces las dificultades de la profesión y la necesidad de avanzar hacia otros caminos, hacen tomar senderos no imaginados, como es el caso de su protAgonizo, una obra al estilo monólogo, en el que convierte su propia biografía casi en un diálogo consigo misma, siendo el público su otro yo, que la escucha, la analiza y la comprende o no, ya sea en los aciertos como en los errores. Me quedo con lo que fue el titular que puse a este trabajo "texto valiente y gran interpretación" (Castro 2009d), porque se corresponde con el personaje, que es la persona que desnuda en escena de principio a fin, su cuerpo y su vida con el pudor que todos podemos tener, pero con la decisión de quien sabe lo que quiere y debe llevar a cabo. El éxito de este trabajo no estaba en la agenda, y comienza como una necesidad de escribir por parte de su autora y protagonista, para irse convirtiendo a lo largo de unos meses, en lo que es ahora y llevamos presenciando desde hace un año en las salas madrileñas (Montacargas, Triángulo) pero también en otras de otras ciudades españolas, sin interrupción.

\section{LOS FORMATOS DANZA Y TEATRO DANZA}

La danza es la hermana maltratada de las artes escénicas, salvo cuando se trata de un gran ballet ruso, de compañías de danza clásica o similar. A ojos del público, la danza contemporánea ha sido considerada un género colateral que, salvo en sus ciclos 
específicos, no tiene especial interés en los circuitos escénicos. Poco a poco me ha ido conquistando, transmitiéndome unos contenidos que convierten los diferentes estilos de lo que voy conociendo (principalmente dentro de los trabajos que se generan en Madrid), en un aspecto de sumo interés, incluso necesario por sí solo o combinado con una acción más teatral. El abanico de expresión abarcable por la danza no tiene límites. Roto el círculo exclusivo de la danza clásica, es posible apreciar nuevos y diferentes valores que creo, merecen ser destacados en el panorama actual. No se trata de desprecio por la danza clásica, que tengo la oportunidad de seguir ocasionalmente en algunos grandes teatros comerciales, sino del sentido del formato y la innovación que supone la contemporánea en las salas alternativas, pero también de casos como el del flamenco. Es destacable que en Madrid existan diferentes eventos anuales dedicados a la danza, que se mueven en las salas alternativas. Entre ellos quiero destacar un evento pequeño (en cuanto a duración y presupuesto), como es el Festival Internacional de Danza Miradas al Cuerpo, ideado hace más de tres años por la bailarina y profesora Maite Larrañeta, y que este año ha cumplido su tercera edición en el Teatro LaGrada (otra de las excelentes salas alternativas del entorno del barrio de Embajadores). A lo largo de cada convocatoria, distint@s profesionales de la danza exponen un trabajo o conjunto de trabajos, sea de manera individual o colectiva, cambiando de coreografía y de protagonistas cada semana a lo largo del mes de septiembre y parte de octubre. En los dos últimos años he podido tener la inmersión en este festival con gente como Leilani Weis, con su trabajo homenaje a Salvador Allende y a lo sufrido por los chilenos durante la dictadura, por medio de su trabajo titulado La aparecida, o con Mar López y Anuska Alonso en su estilo contact danza que muestran en A 2 centímetros del suelo. A Diana Bonilla y Ana Sánchez Couso en un estilo de improvisación que se recoge en su trabajo Duet. En el caso de la muestra de este año (aún no finalizada al escribir este texto), soy capaz de sorprenderme con el trabajo de María Cruz Planchuelo, que bajo el título de El Telar de ...Durga Gea Danu..., transmite la esencia de "ese telar de la diosa tríada entre la oriental Durga, la madre griega Gea o la irlandesa Danu, que quedará a disposición del observador al final del trabajo, generando incluso un punto de impresión en la diosa-mujer, que en el fondo es algo reflejo de la parodia del imposible dios trino de la mitología católica, o del conjunto de las tres mitologías monoteístas modernas, en ninguna de las cuales se contempla a la mujer salvo como reproductora servil" (laRepúblicaCultural (Especial, compendio de artículos) 2010), como recojo en su momento en la reseña a propósito de la obra. Aunque hay más en este festival, quiero destacar el trabajo de Maryluz Arcas, que junto a Koke Armero desarrolla un trabajo sugerente en El monstruo de las dos espaldas, paralelismo entre el nacimiento, crecimiento, desarrollo y muerte de un ser humano con respecto de una relación, que sigue los mismos pasos, desde el nacimiento a las consecuencias de la pérdida. Maite Larrañeta como organizadora de este festival, merece mención también 
por su trabajo en el montaje ¿Qué harías tú si fueras Medea? (Castro 2009a), donde en formato danza ofrece una visión (basada en la Medea de Christa Wolf) que plantea mirar con los ojos de ver a una mujer actual, como alternativa a la tradición de Medea y Jasón. Un trabajo sumamente interesante, ya sea por el planteamiento, como por el diseño y la ejecución, que rompe algunas barreras entre lo clásico y lo actual sin juicios de valor preestablecidos.

El flamenco, siempre relegado a pequeños espacios, con el significado del tablao, y el entorno que proporciona el significado de sus orígenes, con el tiempo sufrió una transformación en gran espectáculo trasladado a los grandes teatros como hecho comercial. Hoy día, otras formas del flamenco surgen en Madrid, que no ha dejado de ser un centro neurálgico para este género, en la música, el cante o la danza. Se me hace imprescindible citar a un jovencísimo personaje que, pese a sus apenas 21 años, viene poniendo en marcha montajes desde que contaba con una edad de 9. Hablo de Selene Muñoz, un hecho curioso que, proveniente de padre sevillano y madre danesa, se inició en la danza desde muy corta edad, para volcarse de lleno en el flamenco casi desde el primer momento. Su capacidad para absorber, transformar y transmitir lo procesado, la convierte en el gran fenómeno de ese baile flamenco, donde la parte de fusión tiene su peso, y el fruto de la improvisación ofrece el resultado que pretende Selene. En sus propias palabras: "transmitir a la gente y que no hagamos algo puramente estético, o sólo físico o musical, sino que todo tenga un 'por qué', que sea un conjunto de emociones, de estética y de muchas cosas" (Castro 2010q). Dos montajes a destacar son Con los cinco sentidos (Gigosos 2008), con varios años de giras, y el reciente Cartas de amor (Castro 2010ñ), con un estilo que conjuga lo teatral y la danza de base flamenca, $\mathrm{y}$ al que acopla otros estilos.

\section{LA ENSEÑNAA NO FORMAL EN EL TEATRO.}

Parte fundamental del teatro que vivimos en la ciudad de Madrid, es resultado del trabajo de muchas personas dedicadas a la preparación o a la especialización de quienes luego posibilitan la ejecución de esa labor frente al público. Si bien tenemos por una parte la educación formal de un centro de formación reglada (en este caso la RESAD), numerosas personas de este entorno opinan que, si bien la formación oficial es muy completa, en ciertos aspectos no proporciona la salida deseada, o bien se ha quedado obsoleta en otros aspectos. Sin profundizar en el acierto de quienes afirman o niegan estos términos, estoy en condiciones de asegurar que una gran parte de la formación artística se mueve fuera de dicho centro. Prácticamente, cada sala es un centro de formación, de manera que algunos cubren más y otros menos tipos de especialidad (y con mayor o menor eficacia). La lista sería larga, y quiero citar a algunas de las mismas, con las que he podido tratar, o a cuyos resultados he accedido de alguna manera. 
Maite Larrañeta, profesora del Conservatorio Superior de Danza "María de Ávila", y también en la escuela del Teatro Lagrada, plantea que "hay tres aspectos que considero fundamentales para la formación de un intérprete de danza: la exploración, la capacidad de análisis y la práctica escénica". En el desarrollo de estas tres claves, converge con otras formadoras, al afirmar "no deben dejarse las presentaciones únicamente para un examen o evaluación, debe ser algo mucho más cotidiano. Así el intérprete aprende sobre las tablas a comunicarse con el público y el coreógrafo tiene ocasión de ver si funcionan o no sus propuestas", y esto es precisamente lo que proporciona un mayor impulso y sentido a las escuelas de cada sala teatral.

La mexicana Angélica Briseño, afincada en Madrid y que imparte su docencia en La Usina, dentro del ámbito de Entrenamiento e Investigación de la Voz, asegura que se dedica a ello "para enseñar, porque no consigo otra forma de enseñar que no sea aprendiendo. Me descubro muchísimas cosas enseñando", y en su materia, vuelca su línea de enseñanza en "el trabajo de encontrar tu cuerpo y tu voz como una misma cosa, de ver otras posibilidades en lo creativo, que no tiene que ser la historia, o lo que cuenta o lo que se escucha bien, o los gorgoritos,... sino trabajar desde la desestructuración, el rompimiento, la no-lógica, la fantasía, el juego..." (Castro 2010r).

Ya citaba a Selene Muñoz que a sus 21 años, lleva varios de ellos dedicada a la docencia que valora casi tan importante como la investigación, al igual que Maite Larrañeta, y como la danza a la que se dedica. No obstante, puesta a optar se decanta por "bailar, porque mucha gente también aprende viendo, pero sobre todo, porque es el momento en que puedes hacer algo que transmites". Selene imparte clases en el centro Amor de Dios, pero también cursos y seminarios en otras capitales europeas, además de su reciente paso por Japón.

Rocío Mostaza, aborda otro tipo de enseñanza, dirigida a los más jóvenes, que en sus inicios se enfocó al trabajo en zonas deprimidas de Madrid, en programas de animación a la lectura y de igualdad y cree que "hay que tocar a la sociedad para que vaya cambiando sus malos hábitos, pero donde está la pureza es en la infancia, y si ésta lleva una educación potente, será una sociedad fuerte". También basa sus métodos de trabajo en la investigación, pero su característica principal en la formación, consiste en orientar cada uno de los caracteres de los niños, mediante un trabajo en grupo en el que evita los protagonistas principales que destacan frente a otros, pero recalca que investiga junto con sus alumnos, aprendiendo de ellos y de sus resultados.

Los resultados del trabajo de la profesora de origen argentino Milagro Lalli, docente en la sala Cuarta Pared, me llevaron a indagar sobre algunos aspectos referentes al mismo tras ver el montaje de ¡Vaya Regalo!, obra para todos los públicos con la dualidad de la base teatral y la de la danza. Como profesora de movimientos, me señala que "intento que el trabajo del cuerpo no se estanque solo en lo físico, sino en 
establecer vínculos con otras áreas artísticas que despierten y motiven el trabajo dando mucha libertad a los intérpretes. Más allá del trabajo consciente referente al cuerpo, existe una estimulación continua impulsada por la música, los sonidos, la pintura, la escultura, el texto y la imagen. Me parece necesario estimular a la gente y abrir las perspectivas a otros campos artísticos para enriquecer su mundo intelectual y con ello el creativo". No es casual el resultado que puede apreciarse claramente en este trabajo escénico, tal y como veremos.

\section{TEATRO FAMILIAR O PARA NIÑOS}

En este apartado encontramos dos líneas principales paralelas, consistentes en un teatro de mayor profundidad y otro más ligero. Ambos contemplan una función educativa, así como la del entretenimiento y la diversión, ya que de otra manera, sería casi imposible captar la atención del público más joven. Al margen de estas dos líneas, existe un sinfín de matices que utilizan las compañías que se dedican a ello, pero quiero recalcar que este ámbito escénico se caracteriza por estar más poblado de mujeres que el teatro para adultos y muchas compañías se componen de mujeres en su mayoría o en la totalidad. Por ejemplo, la compañía Los Gorriones, que dirige Enara Navarro, en la que trabajos como Un paseo por el mar, Aqua, 1, 2, 3 imagina o La lavadora Dora, se dirigen a un público eminentemente de corta edad, con trabajos de su propia creación en los que usan siempre un fondo de guiñol con mayor o menor peso en la parte interpretativa, ya que puede servir de apoyo o constituir hasta el $50 \%$ de la función, compartiendo escena con alguna de las actrices y volcando su propio saber hacer, que consigue que desde el primer instante salten de sus asientos y participen en la obra, sin necesidad de mucha más motivación. Estos trabajos siempre cuentan con un trasfondo educativo, pero también con algún mensaje social que niños y niñas captan de manera natural y, como señalaba en su momento, el público más pequeño participa "desde el primer momento, como si les hubiesen puesto un resorte en el culo antes de empezar. Con canciones y juegos, algunos suben al escenario sin miedo [...] Nunca seré capaz de comprender (como adulto), qué mueve a niños y niñas ante una obra de teatro, a interactuar sin necesidad de que se les diga nada" (Castro 2010d). La compañía Creaciones Colectivas, que dirige Rocío Mostaza (ya citada) junto a las otras actrices de la compañía ofrece en su obra El Lazarillo ¡Un niño de mundo! una visión alternativa del personaje, permitiéndose introducir connotaciones sociales actuales, sobre la marginación y la discriminación. El trabajo de Milagro Lalli y la compañía Cuarta Pared ¡Vaya Regalo!, de gran plasticidad en formas, movimientos, intérpretes, escenario y colorido, consigue llegar en el doble formato de la danza y el teatro a públicos de cualquier edad. Como reseñé en su día, creo que se trata de "un trabajo muy físico mezclado con música y textos rimados, de un nivel tan sencillo como 
complejo se quiera ver, pero con una gran expresividad, en la que han sabido encajar muy bien el lenguaje de personitas mayores que tienen [los pequeños] cuando ponen pose de seriedad, cuando quieren algo, o cuando aseguran alguna 'verdad innegable'"' (Castro 2010i). Simplemente han sabido generar el ambiente adecuado, engranar las piezas de danza, teatro y escenografía, con el contenido y los objetivos del trabajo original, consiguiendo algo que ofrecer tanto a niños como a adultos. Su autora afirma que "mi objetivo fue seguir siendo fiel al código de comunicación que a mí me interesa y no subestimar la capacidad intelectual de los niños", ya que para ella se trata de "un público muy sincero y sin complejos en la respuesta, inteligente y también vulnerable".

Creo que es interesante estar atentos a una compañía tan joven como la Merendarte, y a su primer trabajo La merienda de los locos, basada en un análisis de la Alicia de Lewis Carroll, y que cuenta con una gran profundidad que alcanza a los más pequeños, pero también a los adultos, y en la que sus tres actrices Pau López-Bravo, Laura de la Paz Rico y Sol Romero, (junto a Mario Núñez Ronda en el papel del Sombrerero) hacen un gran papel, especialmente Sol Romero, interpretando a una enloquecida y pérfida liebre. No quiero olvidarme de citar a Teatro Porsiacaso (con Pilar Gil, Iratxe Gallardo, Zoe Sepúlveda), compañía a la que pude ver hace unos años, con su obra La niña invisible, de Rita Siriaka, trabajo muy volcado en el tema del la xenofobia, las fronteras y la exclusión social, con la que llevan a cabo una gran labor educativa, además de resultar una gran provocación para el público infantil.

\section{LAS SALAS TEATRALES}

Una de las apuestas más interesantes de la escena madrileña viene marcada por la creación de las salas alternativas. Actualmente, la denominación se va transformando en el de salas de pequeño formato, por cuanto que algunas pretenden identificarse como "algo opcional" a otros teatros, sino como una diferenciación de esos grandes teatros comerciales, cada vez con mayor concentración empresarial, y orientados a una opción volcada más en el entretenimiento basado en el glamour, en tanto que las alternativas se centran más en la creatividad cultural teatral (nunca exenta del carácter de espectáculo que entretiene e interesa, y que está al alcance de todo aquel al que le gusta el teatro). Sería preciso un largo recorrido por las distintas salas alternativas madrileñas, que poco a poco vengo realizando desde hace unos meses, recogiendo las peculiaridades más inmediatas de cada una, mediante entrevista a sus director@s y programador@s, trabajo que en poco tiempo se verá concluido en su primera fase, a fin de poder profundizar después en otros aspectos referentes a detalles más específicos de actividades relacionadas con las salas. Lo fundamental es que estos espacios constituyen el soporte para la actividad más efervescente de la escena madrileña y que, de no existir, sería preciso inventar, ya que de otra manera no habría espacio para 
las decenas de compañías que se mueven por la escena de esta ciudad. Una cuestión de importancia a reseñar es que la gestión teatral en las salas alternativas demuestra en muchos casos, que la mano de las mujeres proporciona un toque especial y esencial para esa vida que se maneja en su interior. Contamos con salas dirigidas y gestionadas por mujeres, como es el caso de la sala Liberarte, ubicada en el barrio de Tetuán, y más alejada del núcleo teatral habitual. Dirigida y gestionada por Yolanda L. García, que lleva al frente de la misma y de su programación prácticamente tres años, e incluye una escuela teatral, que ella misma dirige. Cuenta con un reducido grupo de trabajadoras, y su programación tiene una vertiente que se inclina especialmente al teatro para la infancia (con producciones y coproducciones propias), pero también gestiona una programación de adultos vinculada en su mayor parte al teatro contemporáneo como sala que se encuentra más alejada del centro urbano, y sin otros espacios teatrales en su entorno, ve dificultada la difusión de sus actividades, y es aquí donde se puede comprobar que un entorno más diverso, potencia la gestión cultural, pero además Liberarte se enfrenta a un entorno más impenetrable para el teatro en sala. un caso similar, es la sala El Montacargas, ubicada al otro lado del río Manzanares y que con casi dos décadas de existencia, es una de las veteranas en el espacio teatral alternativo. La programación de este teatro corre a cargo de Aurora Navarro, creadora de la misma junto con Manuel Fernández, así como de la compañía del mismo nombre, que supera las dos décadas de actividad escénica. Una de las especialidades de la programación que elabora Aurora consiste en la organización de ciclos, como el Clown, festival que ha durado 14 años hasta que la administración madrileña le cortó la subvención. También cuenta con un ciclo anual dedicado a la mujer entre marzo y abril, y otro de creadores del espacio madrileño, denominado MATEM. Como en todas las salas pequeñas, la vida de El Montacargas no ha sido fácil, pero tiene el hándicap añadido de su ubicación en un barrio obrero del extrarradio fluvial, aunque es un edificio con un gran encanto y donde las tres trabajadoras de la sala (además de Aurora y Manuel) proporcionan una atención muy profesional, dentro de un ambiente que se respira (y es) familiar. Plot Point es un espacio peculiar que, como muchas salas surge de la necesidad de una compañía teatral. Su directora de programación, Marina Skell, es también autora de algunas de las primeras obras de la compañía, con la peculiaridad de que, pese a no ser intencionado, ha devenido en un lugar donde hay cierta preeminencia por el teatro hecho por mujeres (que no para mujeres), de forma que diversas compañías de peso femenino, aparte de la de la propia sala, recalan en este espacio de escenario diminuto, en la medida de las posibilidades. En un estilo muy cabaret en cuanto a su distribución, permite, sobre todo, dar a estudiantes de su escuela la posibilidad de estrenar o ensayar sus trabajos, subiéndose a escena varias veces durante su formación. Nudo Teatro, una sala muy reciente, se inserta en un nuevo entorno que ellos han contribuido a crear en la calle de La Palma, donde varios locales asocian sus 
esfuerzos para impulsar una oferta teatral y cultural amplia. Cuenta con dos socios y dos socias, con distinta vinculación profesional al teatro, como son la interpretación, la escenografía arquitectónica o las artes plásticas. Son Eva Caballero, Viviana Vasco, Ángel Málaga y Doriam Sojo, quienes mantienen ese pulso sostenido de los comienzos de un espacio teatral que, con medios realmente precarios, han querido apostar por la difusión en todo el entorno del barrio de Malasaña. Otros lugares con más experiencia o más recientes, y de distintas características, entre ellos la sala siempre presente Pradillo, donde el espacio mujer es destacado en su gestión y en su programación; por supuesto el teatro LaGrada, en el entorno del barrio de Embajadores, al igual que la joven sala La Usina, donde veremos a Angélica Briseño entre las docentes de teatro, o Tarambana, en Carabanchel la parte más alejada respecto a las salas alternativas. Otras más diminutas como la Escalera de Jacob, y algunas con programación más específica como Espacio DT (también del núcleo más veterano de estas salas), o la sala TIS, en el entorno Lavapiés. Todo ello merece el estudio aparte que está pendiente de publicación definitiva en estos momentos, con un trabajo de investigación avanzado y muy extenso.

\section{REFERENCIAS BIBLIOGRÁFICAS}

Álvarez, J., “Perros en danza: ¡Mientras en España siga reinando dios, no habrá república posible!". laRepúblicaCultural. Edita: laRepúblicaCultural.es. Internet 25-06-10. http://www.larepublicacultural.es/article2909.html

Bellver, E., protAgonizo, Madrid, ROTURA, 2010

Castro, J., “La niña invisible pasó por el teatro de Montánchez en su tercera edición”. laRepúblicaCultural. Edita: laRepúblicaCultural.es. Internet 4-09-08. http://www. larepublicacultural.es/article1001.html

Castro, J., “Una Medea fuera de la tradición y en formato danza, de la mano de Maite Larrañeta". laRepúblicaCultural. Edita: laRepúblicaCultural.es. Internet 15-07-09a. http://www.larepublicacultural.es/article1870.html

Castro, J., "Maite Larrañeta: 'lo realmente alternativo se gesta en las trastiendas de escuelas, centros culturales, espacios de ensayos'”. laRepúblicaCultural. Edita: laRepúblicaCultural.es. Internet 22-07-09b. http://www.larepublicacultural.es/ article1891.html

Castro, J., “No hay perdiz en el menú: princesas sin príncipe salvan princesas de caer en la trampa". laRepúblicaCultural. Edita: laRepúblicaCultural.es. Internet 18-1109c. http://www.larepublicacultural.es/article2192.html 
Castro, J., “Ester Bellver pone en escena protAgonizo, texto valiente y gran interpretación". laRepúblicaCultural. Edita: laRepúblicaCultural.es. Internet 22-1109d. http://www.larepublicacultural.es/article2210.html

Castro, J., "Si la iglesia anda por medio, La muerte es lo de menos". laRepúblicaCultural. Edita: laRepúblicaCultural.es. Internet 24-07-09e. http://www.larepublicacultural. es/article3193.html

Castro, J., "El complejo arte del cabaret y la divertida sencillez de sus integrantes, en Le Petit Cabaret des Horreurs et des Perversions". laRepúblicaCultural. Edita: laRepúblicaCultural.es. Internet 10-01-10a. http://www.larepublicacultural.es/ article2338.html

Castro, J., "Ester Bellver: 'la cultura está muy "valorada", hay importantes marcas que lavan su cara promocionando eventos culturales'”'. laRepúblicaCultural. Edita: laRepúblicaCultural.es. Internet 10-01-10b. http://www.larepublicacultural.es/ article2339.html

Castro, J., "Clownas Revolution, cinco espectáculos en uno: Humor y furor". laRepúblicaCultural. Edita: laRepúblicaCultural.es. Internet 25-01-10c. http://www. larepublicacultural.es/article2376.html

Castro, J., "El mensaje constructivo de Un paseo por el mar". laRepúblicaCultural. Edita: laRepúblicaCultural.es. Internet 08-02-10d. http://www.larepublicacultural. es/article2434.html

Castro, J., “Dale Que Dale Teatro: 'Reivindicamos el papel de la mujer para salir de los clichés en que nos han encasillado, pero no nos dirigimos sólo a mujeres"'. laRepúblicaCultural. Edita: laRepúblicaCultural.es. Internet 22-02-10e. http://www. larepublicacultural.es/article2489.html

Castro, J., “Un bosque y la imaginación motivos para los peques en 1, 2, 3... Imagina”. laRepúblicaCultural. Edita: laRepúblicaCultural.es. Internet 23-02-10f. http://www. larepublicacultural.es/article2491.html

Castro, J., "Matar por matar en clave de humor, hasta morir de la risa". laRepúblicaCultural. Edita: laRepúblicaCultural.es. Internet 28-02-10g. http:// www.larepublicacultural.es/article2512.html

Castro, J., "Cualquier definición es buena para la Cáscara amarga de Pombo Teatro". laRepúblicaCultural. Edita: laRepúblicaCultural.es. Internet 18-03-10h. http:// www.larepublicacultural.es/article2576.html

Castro, J., "La discriminación sexual, a través de enredos sencillos, en Titanias". laRepúblicaCultural. Edita: laRepúblicaCultural.es. Internet 23-03-10i. http://www. larepublicacultural.es/article2593.html 
Castro, J., “Un divertido ejercicio de responsabilidad en ¡Vaya regalo!”. laRepúblicaCultural. Edita: laRepúblicaCultural.es. Internet 16-04-10j. http://www. larepublicacultural.es/article2677.html

Castro, J., "Si no han visto a Desheredadas Teatro, aún no han visto todo". laRepúblicaCultural. Edita: laRepúblicaCultural.es. Internet 19-05-10k. http:// www.larepublicacultural.es/article2793.html

Castro, J., “El deseo se disfraza de Premonición”. laRepúblicaCultural. Edita: laRepúblicaCultural.es. Internet 10-06-101. http://www.larepublicacultural.es/ article2868.html

Castro, J., "Un extenso catálogo de perversos en el cabaret de los Monstruos". laRepúblicaCultural. Edita: laRepúblicaCultural.es. Internet 09-07-10m. http:// www.larepublicacultural.es/article2973.html

Castro, J., "Del cabaret a la serie televisiva, con Mise en Sène de La Xirgu". laRepúblicaCultural. Edita: laRepúblicaCultural.es. Internet 26-07-10n. http:// www.larepublicacultural.es/article3047.html

Castro, J., "Del flamenco al rock clásico con las Cartas de amor de Selene Muñoz". laRepúblicaCultural. Edita: laRepúblicaCultural.es. Internet 12-08-10ñ. http:// www.larepublicacultural.es/article3089.html

Castro, J., “Teatro LaGrada: ‘en nuestra dimensión, tenemos algún grado de libertad más que las salas comerciales'”'. laRepúblicaCultural. Edita: laRepúblicaCultural. es. Internet 19-07-10o. http://www.larepublicacultural.es/article3020.html

Castro, J., "Cuarta Pared: 'queremos hacer un teatro que no sea parte de la cultura del ocio, sino que trascienda'”'. laRepúblicaCultural. Edita: laRepúblicaCultural.es. Internet 17-08-10p. http://www.larepublicacultural.es/article3102.html

Castro, J., "Selene Muñoz: 'cuando un artista sube a un escenario, tiene que salir limpio, no se puede utilizar el arte para limpiarse'"'. laRepúblicaCultural. Edita: laRepúblicaCultural.es. Internet 9-09-10q. http://www.larepublicacultural.es/ article3174.html

Castro, J., “Angélica Briseño: ‘Una escuela cabal, es aquella donde la enseñanza te haga un animal creativo y no estés a expensas de lo que te enseñen"'. laRepúblicaCultural. Edita: laRepúblicaCultural.es. Internet 15-09-10r. http://www.larepublicacultural. es/article3193.html

Castro, J., “Teatro El Montacargas: 'en otras comunidades hay mayor inteligencia a la hora de cuidar sus productos, aquí, si hay un gran fasto, se trae a alguien de fuera'". laRepúblicaCultural. Edita: laRepúblicaCultural.es. Internet 22-09-10s. http://www. larepublicacultural.es/article3222.html 
Clownas, "Dossier de Clownas, Compañía de Payasas", Clownas. Edita: laRepúblicaCultural.es. Internet 14-08-10 www.clownas.blogspot.com

Despeyroux, D., Díptico del más allá, Barcelona, Montesinos/Teatral, 2010 Despeyroux, D., Bienvenido a Girasol, Buenos Aires, Teatro a la Intemperie, 2008 Despeyroux, D., Terapia, Granada, Editorial Universidad de Granada, 2005

Gigosos, M., “La otra mirada del flamenco, de Selene Muñoz”. laRepúblicaCultural. Edita: laRepúblicaCultural.es. Internet 7-08-08. http://www.larepublicacultural.es/ mot105.html

González, C., “El Lazarillo, ¡Un niño de mundo!, la obra de Creaciones Colectivas”. laRepúblicaCultural. Edita: laRepúblicaCultural.es. Internet 17-10-08. http://www. larepublicacultural.es/article365.html

laRepúblicaCultural.es, "II Festival Miradas al Cuerpo 09 (Especial)”. laRepúblicaCultural. Edita: laRepúblicaCultural.es. Internet 10-11-09. http://www. larepublicacultural.es/mot105.html

laRepúblicaCultural.es, “III Festival Internacional de Danza “Miradas al Cuerpo" 2010 (Especial)”. laRepúblicaCultural. Edita: laRepúblicaCultural.es. Internet 10-09-10. http://www.larepublicacultural.es/mot148.html

Martínez, P., Margallo, J., ados@dos Madrid, Huerga y Fierro, 2008, pp. 25.

O'Connor, P.W, Mujeres sobre mujeres en los albores del siglo XXI: teatro breve español, Madrid, Fundamentos/Teatro, 2006

Wainer, M. "Breve Curriculum de Marina Wainer" Marina Wainer. Edita: Marina Wainer Internet. 15-08-10. http://marinawainer.com/novedades/curriculum/ 